\title{
QUALITY MANAGEMENT IN UNDERGRADUATE EDUCATION FROM THE PERSPECTIVE OF SCHEIN'S CAREER ORIENTATIONS INVENTORY
}

\author{
NICA COTET, G[abriela] B[eatrice]; GEORGESCU, L[uminita] E[lena]; \\ DRAGOI, G[eorge] \& ROSU, S[ebastian] M[arius]
}

\begin{abstract}
The purpose of this paper was to reveal the link between the human resource profile of the school education and profiles described by Schein in terms of education quality management. The Career Orientations Inventory was applied in order to emphasize the link between profit and quality of human resources. Education and training providers are at the base of the education and training system in that they are the organizations that actually engage in teaching and learning and deal directly with learners. It is therefore of great importance that providers develop quality management systems (QMS)

Keywords: education quality management, relevant profiles, career orientations inventory
\end{abstract}

\section{INTRODUCTION}

Development through excellence, expertise and knowledge is an important part of the process of education, resulting both in school and at university level, a process which should not be compromised in terms of create. This required a good strategy for the development of undergraduate education in almost all countries. Determination of the position of the leader, to create a perspective, it is connected with a high-school education system where the criterion is efficiency. The future of any nation depends in large measure on investment in continuous training and development of human resource involved in education.

The new economic growth theories have emphasized the role of human capital as the key of economic growth and development. The aim of the research is to explore new acquaintances as the enlargement function focuses on developing application of knowledge developed to address common issues of society.

Continuing education and training are the basic principles that must be followed when we speak of the development of a quality education, attention focuses on the models chosen by the self-improvement involved in the process of learning. It is therefore of great importance that providers develop quality management systems (QMS), and that they receive the necessary support in order to operate within the National Qualifications Framework (NQF). The significance of implementing a Quality Management System involves a combination of processes in place to ensure the degree of excellence.

A quality management system is represented by the activities and information used to allow the provision of services which exceed the needs and expectations and represent a cost effective both at present and in the future

\section{THE EDUCATION QUALITY MANAGEMENT}

The word "quality" derives from the Latin word quails, which means "what kind of". Nowadays this involves a variety of meanings and implies different things to different people. According to Juran (1989) "Quality is fitness for use or purpose" [1]. Deming (1986) defines quality as "a predictable degree of uniformity and dependability at low cost and suited to market" [2].

In general terms, quality means a satisfying imposed by certain standards and rules of professionalism.

According to Murad and Rajesh (2010) quality in education has the following dimensions [3]:

Consistency: the educational process involves specifications through zero defect approach and a quality culture. The limitations are in achieving consistent standards and conformity to those standards. Consistency is an approach to quality that emphasises the need to eliminate errors.

Fitness to purpose: fitting the customer specifications, minimum-based fitness for purpose and customer satisfaction. Fitness for purpose has been a widely used approach by quality agencies. The notion derives from manufacturing industry that purportedly assesses a product against its stated purpose.

Value for money: through efficiency and effectiveness.

Transformative: education is an ongoing process of transformation that includes empowerment and enhancement of the customer. This dimension reflects the limits of knowledge, the certainty of knowledge and the criteria for knowledge.

TQM can be defined as "the process of integration of all activities, functions and processes within an organization in order to achieve continuous improvement in cost, quality, function and delivery of goods and services for customer satisfaction". It refers to the application of quality principles to overall process and all the management functions in order to ensure total customer satisfaction. TQM implies the application of quality principles right from identification of customer needs to post purchase services [4].

TQM is the process of changing the fundamental culture of an organization and redirect to the upper items or service quality [5]. 


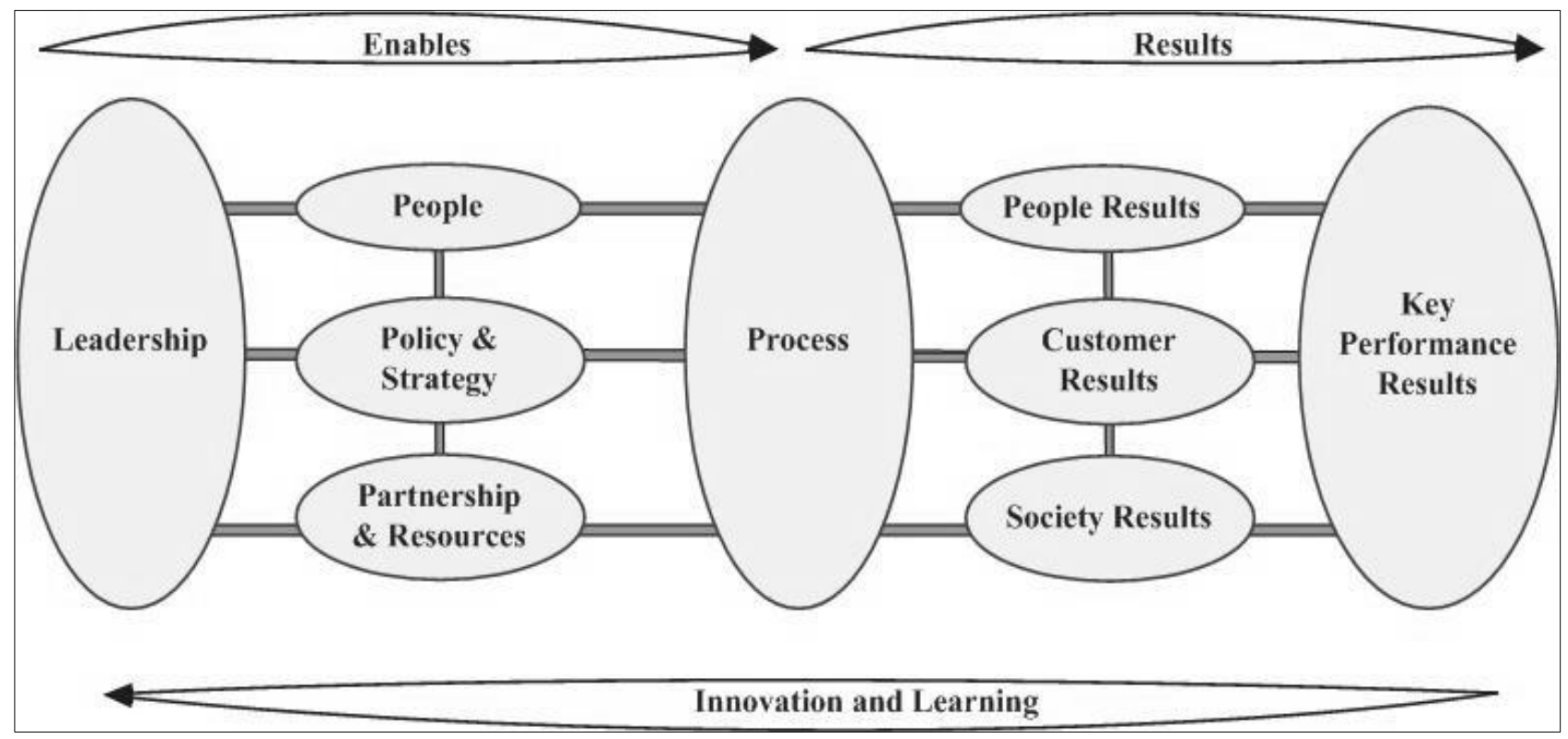

Fig. 1. EFQM Excellence Model [6]

TQM may also be defined as doing things right for the first time, striving for continuous improvement, fulfilling customers' needs, making quality the responsibility of every employee etc.

EFQM Model - EFQM model is a set of systematic criteria articulated presenting various fields of business organization (fig 1).

Through the nine criteria you can understand and analyze the cause and effect relationships between what your organization does and the results you achieve. Five of these criteria are "Enablers" - leadership, people, policy and strategy, partnership and resources and processes and four are "Results" - people results, customer results, society results and key performance results.

The Enabler criteria cover what an organization does and how it does it. The Enabler reflects what is done to activate in terms of quality.

The Results criteria cover what an organization achieves. The Results reflect what has made plans to achieve the quality of organizaratia and banned by the stakeholders, funders and community.

\section{SCHEIN'S CAREER ORIENTATIONS INVENTORY}

The concept of a Career Anchor developed by E. Schein refers to a pattern of self-perceived talents and abilities, basic values, and the evolved sense of motives and needs (as they pertain to the career) that influences a person's career-related decisions [7], [8].

The concept of career anchor reflects on a synthetic form of the person's self image on the role played in the labour. It is a fundamental concept in significance for the individual, an image that builds during the average person with various interactions. As individuals are required to make choices related to their self-evelopment, family or career, they may become more aware of the values and motives that frame the choices they make.
An anchor career develops and stabilizes so that the person gaining experience in professional activity;

In other words, an individual career self-concept acts as a stabilizing force when an important life or career election has to be made. In such a situation there are concerns about specific needs or values that the individual will not give up.

The main career anchors outlined by Schein and measured by his Career Orientations Inventory are presented in the following:

1. Functional or technical competence - T/F is anchor specifies the persons who are attracted by the work itself, which is set up as a factor in intrinsic motivator. Trainee's professional recognition from colleagues and considers opportunities for specialization and selfdevelopment

2. General Management Competence - GMC refers to the need and the ability of people to lead others. Involves the combination of abilities, talents, and skills: analytical, interpersonal and emotional. People identify with this anchor activity and expected to be well-paid, assess immediate rewards.

3. Autonomy or Independence - A/I anchor is specific to people who "feel an overwhelming need to do things as they want them in your own pace and not according to standards established by others. They assess organizational life as being burdensome, irrational and inappropriate with personal life; as such, they prefer to choose careers as independent" [9].

4. Anchor Safety and Stability - $S$ is characteristic of the trainee's organizational environments, predictable with contracts of employment for a period, the trainee's indeterminate employee's loyalty. It is promoted and supported the promotion system based on seniority rather than performance on getting. Is valued autonomy, no constraints of any kind and is preferred self-employment. Rather pay based on performance, accept challenges without autonomy.

5. Entrepreneurial Creativity - EA - is the anchor people with initiative, whose creativity is pointed out especially in business, to obtain above average income and to confirm their successful. 


\begin{tabular}{|l|c|c|l|c|c|c|l|}
\cline { 2 - 8 } \multicolumn{1}{c|}{} & Profiles & Environment & The enrolment & & Profiles & Environment & The enrolment \\
\hline S1 & EA & Rural & High School & S15 & S/DC & Rural & High School \\
\hline S2 & EA & Rural & High School & S16 & SE & Rural & Primary School \\
\hline S3 & EA & Rural & Primary School & $\mathbf{S 1 7}$ & SE & Rural & Primary School \\
\hline S4 & T/F & Rural & Primary School & S18 & SE & Rural & Primary School \\
\hline S5 & T/F & Rural & Primary School & S19 & SE & Rural & Primary School \\
\hline S6 & S/DC & Rural & $\begin{array}{l}\text { Theoretical high } \\
\text { school }\end{array}$ & $\mathbf{S 2 0}$ & SE & Urban & $\begin{array}{l}\text { Technical } \\
\text { school }\end{array}$ \\
\hline S7 & S/DC & Rural & Primary School & $\mathbf{S 2 1}$ & SE & Rural & Primary School \\
\hline S8 & S/DC & Urban & $\begin{array}{l}\text { Theoretical high } \\
\text { school }\end{array}$ & $\mathbf{S 2 2}$ & AU & Urban & High School \\
\hline S9 & S/DC & Rural & High School & $\mathbf{S 2 3}$ & AU & Rural & High School \\
\hline S10 & S/DC & Rural & High School & $\mathbf{S 2 4}$ & LS & Urban & $\begin{array}{l}\text { Theoretical } \\
\text { high school }\end{array}$ \\
\hline S11 & S/DC & Urban & Primary School & $\mathbf{S 2 5}$ & LS & Urban & Primary School \\
\hline S12 & S/DC & Rural & High School & $\mathbf{S 2 6}$ & LS & Urban & High School \\
\hline S13 & S/DC & Urban & Primary School & $\mathbf{S 2 7}$ & LS & Urban & Primary School \\
\hline S14 & S/DC & Rural & Primary School & \multicolumn{5}{l}{} \\
\hline
\end{tabular}

The people with high scores on this scale prefers the challenge of starting new projects or businesses, have lots of interests and energy, and often have multiple projects going at once; different from autonomy in that the emphasis is on creating new business; often pursuing dreams at early age.

6. Serving or Dedication of causes $-S / D C$ is the anchor feature for people who feel a strong need for the aid of other people. People with such anchors shall be centered on the values that people want to personifice them through their work, is shifting towards activities that involve caring for others. Prefer the freedom of action and increasing the influence and recognition of others and share their own values

7. Pure Challenge - PC - is specific anchor people seeking challenge in terms of increased risk, promote competition and achieve high performance, permanent need outstanding achievements and overcoming. Toughest. The promotion is subject to the recognition of the need for autorealizare and is linked to the performance obtained

8. Lifestyle $-L S$ - it is representative of the persons who will be involved in the work, but the trainee's and family life and losir, subscribe to philosophy of "work to live", rather than "live to work". People who get high scores on this scale prefer multi-professional promotion criteria, performance, seniority and multiple and flexible ways of recognizing

\section{CASE STUDY}

The Career Anchor describes the needs, values and self-perceived talents and potential to serve as source of information for assigning roles and expectations in the educational system.

The premise of this article is leaving the university educational system, the main career guidance, described by Schein, would be primarily Service / Dedication to a Cause, followed by Entrepreneurial Creativity. So, we followed Security/Stability scales.

To see that the profiles obtained corresponding to premise from which we started, was applied Schein Career Orientations Inventory's a batch of 27 teachers / educators in the undergraduate system. Results obtained from the inventory are structured following variables: profiles, birthdates, environment and enrolment.

\subsection{Results}

The results obtained from applying Schein's Career Orientation Inventory were summarized in graphs, depending on variables considered relevant in terms of the principle of quality in education.

The application results of the Career Anchors Inventory are presented in Table 1 .

Variable Profiles - percentages obtained for the inventory scales was represented in Figure 2

The highest percentage scale gives it Service/Dedication to a Cause. This confirms the premise of the work: getting a larger number of respondents for this scale. Also we want to reveal and distribution of respondents according to age group (Figure 3).

- Variable Birthdate - applicants were divided into four age groups (Figure 4).

- Variable Enrolment - distribution applicants according to school type in which they work (Figure 5).

It gives the highest percentage of primary school applicants.

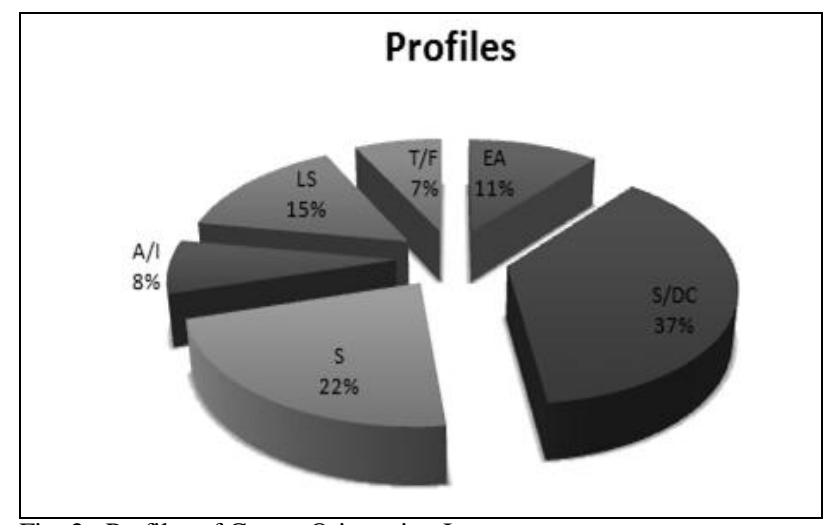

Fig. 2. Profiles of Career Orientation Inventory 


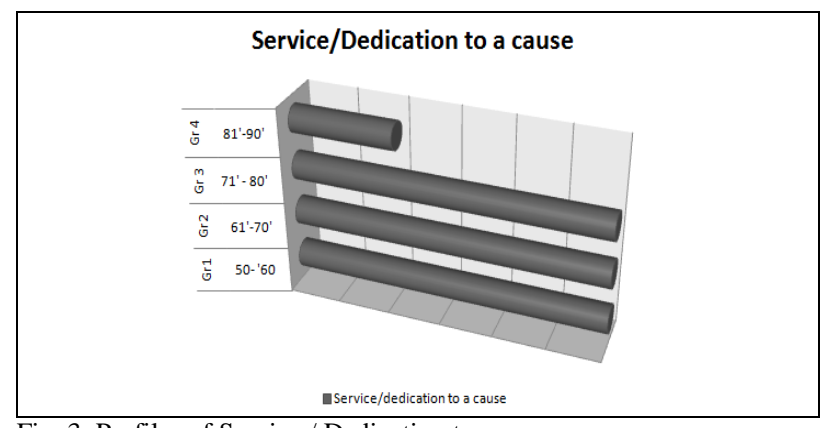

Fig. 3. Profiles of Service / Dedication to cause

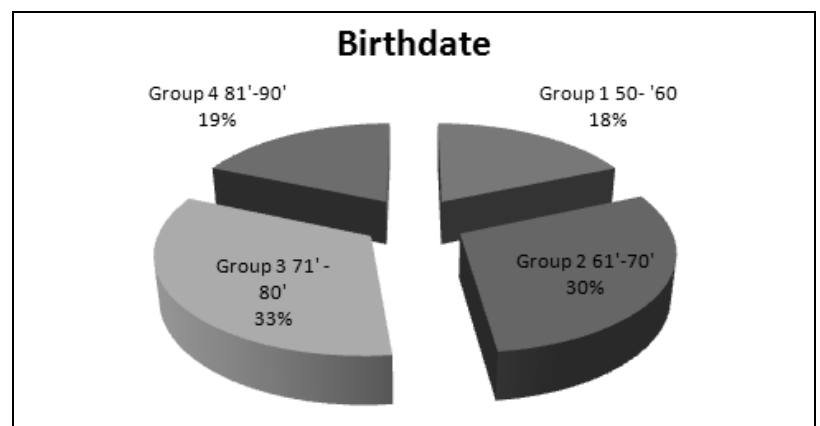

Fig. 4. Variable Birthdates

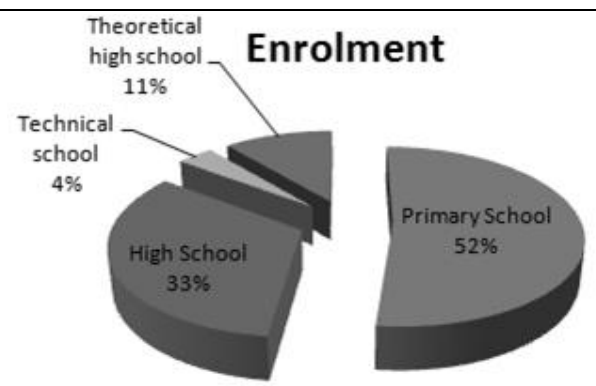

Fig. 5. Variable Enrolment

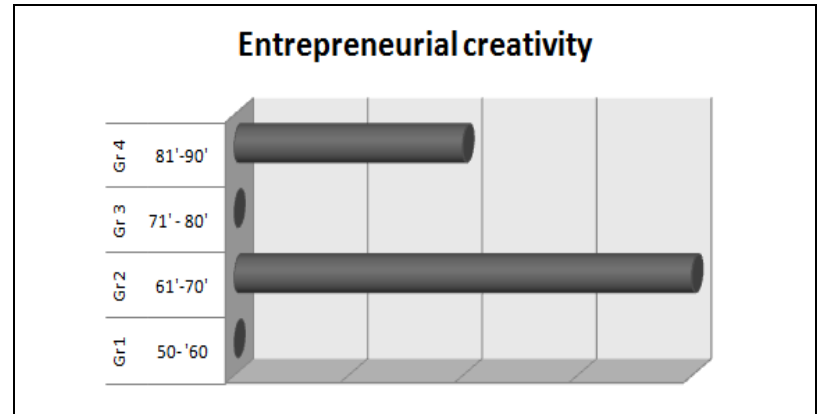

Fig. 6. Profiles of Entrepreneurial creativity

Results from the Security/Stability's profile - are presented in the Figure 7. For the Security/Stability scale we have two grupes with high scores, in opposite with the mean age's groupes.

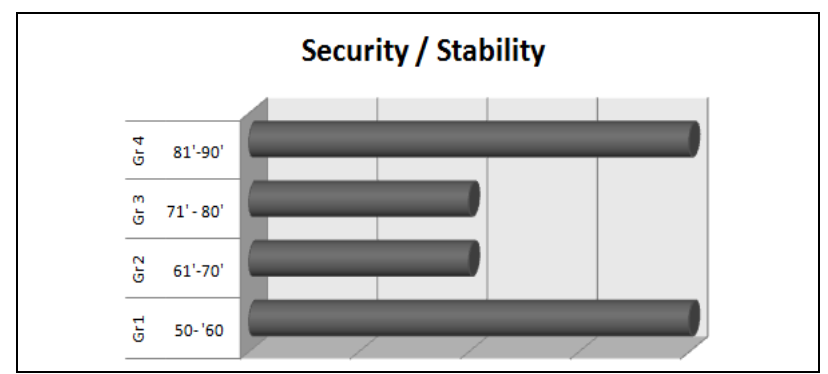

Fig. 7. Profiles of Security/Stability

\section{CONCLUSION}

Quality in education is linked to values and expectations of human resources involved in the educational process. Therefore we can say that the teaching profession is a vocational choice.

This is evidenced by the result achieved after application of Schein's Career Orientations Inventory, through greater percentage the date of the scale "Service / Dedication to a Cause". Note that a factor less positive Security/Stability selection over other scales.

The same time it is important to note and the following results:

- Many teachers rural have Service/Dedication to a cause than teachers urban.

- Older and youngest teachers (50'-60' and 81'-90') will have greater security orientations than mean ages teachers (61' -70'and 71'-80').

- Women will have greater lifestyle orientations than men.

Quality education provides educational actors and valuing human resources. Human resource development and its involvement in the educational process are essential in terms of quality management. Their involvement and professional development depends on how they use their skills to benefit the organization.

\section{REFERENCES}

[1] Juran, J.; (1989). Leadership for Quality: An Executive Handbook, New York: The Free Press

[2] Edwards Deming, W.; (1986). Out of the Crisis - Cambridge, Mass.: Massachusetts Institute of Technology, Center for Advanced Engineering Study

[3] Murad, A. \& Shastri, R. K.; (2010) Implementation of Total Quality Management in Higher Education, Asian Journal of Business Management 2(1): 9-16, ISSN: 2041-8752, Maxwell Scientific Organization

[4] Edwards Deming, W.; (1994) The New Economics, MIT, Cambridge, Mass, European Foundation for Quality Management

[5] Gaither, N.; (1996). Production operations and management, 7th edition, Duxbury Press, Belmont, California

[6] EFQM - Self-assessment Guidelines for Companies, European Foundation for Quality Management. (2003). Brussels,

[7] Schein, E.H.; (1992). Career anchors and job/role planning: The links between career planning and career development. In D.H. Montross \& C.J. Shinkman (Eds.), Career development: Theory and practice. Springfield: Thomas

[8] Schein, E.H.; (1990). Career anchors: Discovering your real value, San Francisco: Pfeiffer Wiley

[9] Vlăsceanu, M. ; (2002). Managementul carierei - Sa învăţăm să ne construim o carieră, Bucuresti:Comunicare.ro 